\title{
Molecular genetic evidence for parthenogenesis in the Burmese python, Python molurus bivittatus
}

\author{
TVM Groot $^{1}$, E Bruins ${ }^{2}$ and JAJ Breeuwer ${ }^{1}$ \\ ${ }^{1}$ Institute of Biodiversity and Ecosystem Dynamics, University of Amsterdam, PO Box 94062, 1090 GB Amsterdam, The Netherlands; \\ ${ }^{2}$ Artis Zoo, Plantage Kerklaan 38-40, 1018 CZ Amsterdam, The Netherlands
}

\begin{abstract}
Parthenogenesis among reptiles is rare. Only a few species have the ability to reproduce asexually. Most of these are obligate parthenogenetic species that consist (almost) entirely of females, which can reproduce solely through parthenogenesis. Rarer are sexual species that only sporadically reproduce through parthenogenesis. A female Python molurus bivittatus (Reptilia, Boidae) from the Artis Zoo, Amsterdam, produced eggs in five consecutive years that contained embryos while she was isolated from males. These eggs might be fertilized with stored sperm, or might be the product of parthenogenesis. Parthenogenesis has not been shown for the Boidae family before. We performed parentship analyses on the snake and seven of her embryos
\end{abstract}

using microsatellites and AFLP. Four microsatellite loci developed for this species combined with three loci developed previously for different snake species revealed too little variation to discriminate between sperm retention and parthenogenesis. With AFLP we were able to confirm that the Artis Zoo female reproduced parthenogenetically. Because the offspring are genetically identical to their mother, whereas in previous studies on sporadic parthenogenesis in snakes a loss of genetic information was reported, we conclude that the meiotic pathways that produce the diploid egg cells are different.

Heredity (2003) 90, 130-135. doi:10.1038/sj.hdy.6800210

Keywords: Python molurus bivittatus; parthenogenesis; microsatellites; AFLP; sperm retention; Reptilia

\section{Introduction}

Sexual reproduction is the predominant mode of reproduction in eukaryotes, and reptiles are no exception to this rule. However, several species of reptiles, all belonging to the order Squamata (lizards and snakes), are known to be obligate parthenogens. Most of these species are thought to have originated from hybridization events between related sexual species (Darevsky et al, 1985). Males are occasionally produced in populations from the wild (Darevsky et al, 1985), but whether these males are fertile and participate in sexual reproduction has not been investigated.

On the other hand, there are numerous anecdotal reports (eg, Magnusson, 1979; Scalka and Vozenilek, 1986), mainly from animals kept in zoos or laboratories, about females of sexual species that are reproduced in the absence of males. This suggests that sexual species have the ability to reproduce by female parthenogenesis. However, an isolated female can also reproduce in the absence of males since reptiles have the ability to store sperm after copulation for long time periods (Fox, 1976; Birkhead and Møller, 1993). Molecular genetic analysis of mother and offspring should allow for an unequivocal discrimination between these two possibilities.

If sexual species reproduce by parthenogenesis, the major problem that has to be overcome is to prevent the

Correspondence: TVM Groot, Institute of Biodiversity and Ecosystem Dynamics, University of Amsterdam, PO Box 94062, 1090 GB Amsterdam, The Netherlands. E-mail: tvmgroot@science.uva.nl

Received 5 June 2002; accepted 25 October 2002 reduction in chromosome number during meiosis, since haploid eggs are inviable. In addition, embryo development must be able to commence without the stimulus of sperm entrance. Suomalainen et al (1987) describe a number of cytological mechanisms that can restore somatic ploidy level. The genetic consequences of parthenogenesis vary depending upon the cytological mechanisms involved; offspring are either completely homozygous or genetically identical to their mother (except for rare mutations). In obligate parthenogenetic reptiles, for example, ploidy level is presumably maintained by premeiotic doubling of the genome in the primary oocytes (Cuellar, 1971; Suomalainen et al, 1987; see also Darevsky et al, 1985). This mechanism results in offspring that is genetically identical to the mother (MacCulloch et al, 1997).

There are a few reports of studies in which molecular genetic methods were used to prove the sporadic occurrence of parthenogenesis in otherwise sexual snakes. The species involved in these studies were Thamnophis elegans and Thamnophis marcianus (Colubridae), Crotalus horridus and Crotalus unicolor (Viperidae) (Schuett et al, 1997) and Acrochordus arafurae (Acrochordidae ) (Dubach et al, 1997). Genetic fingerprints in these species showed differential fixation of maternal heterozygous loci in the offspring. This suggests that offspring become completely homozygous. This is consistent with the observation that all offspring are male. In snakes females are the heterogametic sex (ZW). Homozygous offspring will be either WW or ZZ. Since the WW combination is not viable, all observed offspring are $\mathrm{ZZ}$ and thus male. Although cytological analyses have not 
been conducted, diploidy is probably restored through fusion of the egg nucleus with the second polar body (Schuett et al, 1997), a mechanism known as terminal fusion (Suomalainen et al, 1987).

Here we investigate a possible case of parthenogenesis in a normally sexually reproducing species of snake, the Burmese python (Python molurus bivittatus), a member of the Boidae. The live collection of Artis Zoo in Amsterdam, The Netherlands, contains three adult female P. $m$. bivittatus but no males. One female was born in 1993 at a rescue center and donated to Artis Zoo in 1995. She has been separated from males since her arrival in Amsterdam. In her first 2 years of life she has probably been completely isolated too. She has produced a single clutch every spring starting in 1997 up to 2002. Apparent healthy embryos have been observed in $25-30 \%$ of the eggs in every single year.

We conducted a molecular paternity analysis comparing this female and her offspring using AFLP (Vos et al, 1995) and microsatellite markers (Quellar et al, 1993; McCracken et al, 1999; Lougheed et al, 2000; King et al, 2001). If the offspring were produced by parthenogenesis, each genetic marker in the offspring should also be present in the mother. If, however, the offspring contain additional genetic markers that are not present in their mother, they must have inherited those from their father (except for occasional mutations).

\section{Methods}

\section{DNA isolation and sex determination}

Although our focal female has produced one clutch of eggs every year since 1997, zoo policy did not allow for hatching of python eggs. Since zookeepers were not aware of the possibility of parthenogenesis, no material of the 1997-2000 clutches has been saved for later use in a genetical study. Seven embryos were isolated from eggs of the 2001 clutch after a 24-day incubation period. The embryos then measured about $18 \mathrm{~cm}$. They were separated from the veins that run across the yolk. Blood spilling from these veins was collected for DNA extraction. After blood samples were taken, six out of the seven embryos were dissected at the Veterinary Institute at the University of Utrecht, The Netherlands, in order to determine whether they were male or female. Based on the presence of ovaries, all offspring were identified as female. In addition to the mother (M), two other adult female snakes, both from the Artis Zoo, were sampled. Female 1 is a half-sib of $M$, female 2 is unrelated to the other snakes. In the adult snakes, blood samples $(0.5 \mathrm{ml})$ were taken from the caudal vein. DNA was extracted from $100 \mu \mathrm{l}$ of blood in $300 \mu \mathrm{l}$ CTAB buffer according to the methods of Weeks et al (2000).

\section{Microsatellite markers}

Seven microsatellite loci were used in this study. Four of these, namely, PM-1, PM-2, PM-3, and PM-5 (Table 1) were developed following the methods of Weeks et al (2001). One further locus, HB-30, was originally designed for Hoplocephalus bungaroides (Burns and Houlden, 1999) and two more loci, Ns $\mu-3$ and Ns $\mu-10$, were originally designed for Nerodia sipedon sipedon (Prosser et al, 1999). Eight other loci (HB-2, HB-48, HB-65, and HB-70 (Burns and Houlden, 1999), Ns $\mu-2$ and Ns $\mu-9$ (Prosser et al, 1999), and TS-1 and TS-2 (McCracken et al, 1999)) were also tested but failed to amplify in $P . m$. bivittatus.

The forward primers were $5^{\prime}$ end labeled with $\gamma-{ }^{32} \mathrm{P}$ ATP (Synthetic Oligonucleotides 5'end labeling kit, Fermentas MBI) prior to the PCR. Fragment amplification was done in a $12.5 \mu \mathrm{l}$ PCR reaction volume, containing $1 \times$ Super Taq Buffer (Sphaero Q), $0.16 \mu \mathrm{M}$ of each primer (the forward labeled), $0.2 \mathrm{mM}$ of each $\mathrm{dNTP}$, 0.5 U Super Taq DNA polymerase (Sphaero Q), and $15 \mathrm{ng}$ template DNA. For PM-1 an extra $0.04 \mu \mathrm{M} \mathrm{MgCl}_{2}$ was added. PCR cycling consisted of $3 \mathrm{~min}$ of initial denaturation at $94^{\circ} \mathrm{C}, 36$ cycles of $30 \mathrm{~s}$ at $94^{\circ} \mathrm{C}, 45 \mathrm{~s}$ at primerspecific annealing temperatures and $1 \mathrm{~min}$ at $72^{\circ} \mathrm{C}$, and $5 \mathrm{~min}$ at $72^{\circ} \mathrm{C}$ to end the reactions. Products were run on a $6 \%$ polyacrylamide gel using Sequagel ${ }^{\circledR}$ and $10 \%$ ammonium persulfate (Pharmacia) and exposed to a radiation sensitive film (Kodak $\left.{ }^{\mathbb{R}} \mathrm{X}-\mathrm{OMAT}^{\mathrm{TM}} \mathrm{AR}\right)$ for 2 days.

\section{AFLP markers}

DNA fingerprints were made of all individuals using the AFLP technique (Vos et al, 1995). Typically, AFLP will reveal about 85 dominant markers per primer pair in snakes (Giannasi et al, 2001). Genomic snake DNA was digested and ligated with adapters in two steps. In the first step the DNA was digested with TaqI restriction enzyme. This reaction was done in a $15 \mu \mathrm{l}$ reaction volume containing $125 \mu \mathrm{g}$ DNA, $3 \mathrm{U}$ TaqI, $1 \times$ buffer (One-Phor-All, Pharmacia Biotech), and $5 \mathrm{mM}$ DTT. The reaction mixture was incubated for $1 \mathrm{~h}$ at $65^{\circ} \mathrm{C}$. During the second step, snake DNA was digested by Pst restriction enzyme and ligated with both Taq- and Pstadapters. Straight into the first reaction mixture the second $15 \mu \mathrm{l}$ mix was added containing $0.67 \mathrm{mM}$ ATP, $5 \mathrm{U}$ PstI, 50 pmol Taq-adapter, 5 pmol Pst-adapter, $1.2 \mathrm{U}$ T4

Table 1 Characteristics of the microsatellite primers developed in this study for Python molurus bivittatus. For is the forward primer, Rev is the reverse primer

\begin{tabular}{|c|c|c|c|c|c|}
\hline Locus & Repeat size & Primer pair sequences $\left(5^{\prime}-3^{\prime}\right)$ & $\mathrm{T}_{a}\left({ }^{\circ} \mathrm{C}\right)$ & Fragment size (bp) & No. of alleles \\
\hline PM-1 & $(\mathrm{ATC})_{16}(\mathrm{GTC})_{6}$ & $\begin{array}{l}\text { For - CCA CAG ATC TCC CTC CTA GC } \\
\text { Rev - CAC CAC ACT TTT CTA GGG GC }\end{array}$ & 60 & 211 & 3 \\
\hline PM-2 & $(\mathrm{CAT})_{4} \mathrm{CTC}(\mathrm{CAT})_{6}$ & $\begin{array}{l}\text { For - CCC ACA CCT TTC TAA ATC C } \\
\text { Rev - GCA GAA ACC ATG GAA TTA TG }\end{array}$ & 56 & 208 & 1 \\
\hline PM-3 & $(\mathrm{TG})_{11}$ & $\begin{array}{l}\text { For - CAT TAG ACT GGA TGA GTC C } \\
\text { Rev - GGT TTT CTC CCC AGT TCT C }\end{array}$ & 58 & 209 & 1 \\
\hline PM-5 & $(\mathrm{GT})_{11}$ & $\begin{array}{l}\text { For - CCT CGG GAG AGC CCA AAG } \\
\text { Rev - AAA GTC ACA ACG TTT AGG TAC }\end{array}$ & 59 & 130 & 1 \\
\hline
\end{tabular}




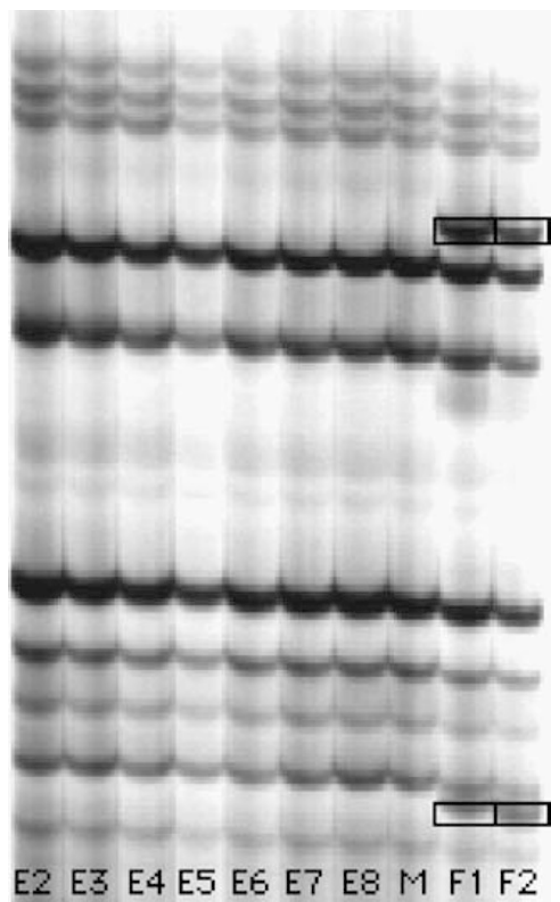

Figure 1 An example of an AFLP fingerprint of P.m. bivittatus. A part of the Pst-ACC with Taq-AT combination is shown. Marked are polymorphic characters that are present in female 1 and female 2 , but are absent in the mother and her offspring.

DNA ligase, $1 \times$ buffer (One-Phor-All, Pharmacia Biotech), and $5 \mathrm{mM}$ DTT and subsequently incubated for $2 \mathrm{~h}$ at $37^{\circ} \mathrm{C}$. Reaction products were then $10 \times$ diluted in $\mathrm{ddH}_{2} \mathrm{O}$ and stored at $-20^{\circ} \mathrm{C}$.

A subset of the created fragments was amplified by PCR in the pre-amp reaction. The pre-amp reaction was done in a $20 \mu \mathrm{l}$ reaction volume containing $0.4 \mathrm{mM}$ of each dNTP, $1 \times$ Super Taq Buffer (Sphaero Q), $1.2 \mathrm{ng}$ PstA primer, $1.2 \mathrm{ng}$ Taq-A primer, $0.5 \mathrm{U}$ Super Taq DNA polymerase (Sphaero Q), and $5 \mu \mathrm{l} 1 / 10 \times$ restrictionligation product. PCR cycling started with 2 min denaturation at $94^{\circ} \mathrm{C}$, followed by 36 cycles of $30 \mathrm{~s}$ at $94^{\circ} \mathrm{C}$, $1 \mathrm{~min}$ at $56^{\circ} \mathrm{C}$, and $1 \mathrm{~min}$ at $72^{\circ} \mathrm{C}$. The reaction was concluded with $5 \mathrm{~min}$ at $72^{\circ} \mathrm{C}$ and $5 \mathrm{~min}$ at $4^{\circ} \mathrm{C}$. Reaction yields were examined by running a sample on a $1 \%$ agarose gel. A successful reaction produced a smear of bands. The remains of the products were diluted $20 \times$ in $\mathrm{ddH}_{2} \mathrm{O}$ and frozen at $-20^{\circ} \mathrm{C}$.

In the subsequent end-amp reactions different subsets of the pre-amp products were amplified with Taq-A primer with a single selective base extra (Taq-AA, TaqAC, Taq-AG, and Taq-AT) and Pst-A with two selective bases extra (Pst-ACC and Pst-AGA). The Pst-A +2 primers were fluorescent-labeled (IRD-700 nm). The DNA library was screened for all eight possible combinations of the mentioned Taq- and Pst-primers. The $10 \mu \mathrm{l}$ reactions contained $1 \times$ Super Taq buffer, $0.5 \mathrm{U}$ Super Taq DNA polymerase (Sphaero Q), $0.4 \mathrm{mM}$ of each dNTP, 25 ng Taq-A +1 primer, 10 ng Pst-A +2 primer, and $2.5 \mu \mathrm{l} 1 / 20$ pre-amp product. Cycle conditions for the end-amp were: $1 \mathrm{~min}$ at $94^{\circ} \mathrm{C}, 13$ cycles of $30 \mathrm{~s}$ at $94^{\circ} \mathrm{C}$, $45 \mathrm{~s}$ at $65^{\circ} \mathrm{C}$, dropping $0.7^{\circ} \mathrm{C}$ per cycle, and $1 \mathrm{~min}$ at $72^{\circ} \mathrm{C}$, followed by another 25 cycles of $30 \mathrm{~s}$ at $94^{\circ} \mathrm{C}, 45 \mathrm{~s}$ at $56^{\circ} \mathrm{C}$, and $1 \mathrm{~min}$ at $72^{\circ} \mathrm{C}$. The reaction was concluded with $5 \mathrm{~min}$ at $72^{\circ} \mathrm{C}$ and $5 \mathrm{~min}$ at $4^{\circ} \mathrm{C}$.
End-amp reaction products were run on a $6.5 \%$ acrylamide gel (6.5\% Ready to use Gel Matrix, KB Plus, Westburg) on an Li-cor IR ${ }^{2}$ Automated Sequencer (see Figure 1). Banding patterns were scored manually.

\section{Results}

Six out of seven microsatellite loci were monomorphic; all individuals were homozygous for the same allele. Only PM-1 showed three alleles. Mother and young were all homozygous for the same allele at this locus too. Female 1 was homozygous for a different allele, and female 2 was heterozygous for the allele of female 1 and a third allele. Thus, the microsatellites did not contain enough variation to discriminate between parthenogenesis and sperm retention.

Three primer pairs developed for snake species from two different families (Colubridae and Elapidae) (Burns and Houlden, 1999; Prosser et al, 1999) amplified DNA fragments in P. m. bivittatus, indicating that these primers amplify in distantly related species. However, they did not yield variation. Variation may be absent because the individuals are highly related, but it may also be that the amplified fragments do not contain the microsatellite repeats. This is unlikely because they were of approximately similar length in the Burmese python as in the species the primers were originally developed for.

A total of 692 AFLP markers were scored from the eight primer combinations (Table 2), 43 (6.2\%) of which were polymorphic markers. One primer combination failed in female 2. AFLP markers are mostly dominant and scored as fragment present (1) or absent (0) (Mueller and Wolfenbarger, 1999). The genotype can therefore not be directly scored, as fragment present can either be a homozygote (11) or a heterozygote (10). Absence of fragments and thus homozygosity (00) can then only be inferred from other (11) and (10) individuals that do have that fragment.

All seven young had identical fingerprints. All the markers of the offspring were also found in their mother. In turn, every marker present in the mother was also present in each of the young. The mother (and her young) differed with her half-sister female 1 in 29 markers of eight primer combinations, and in 30 markers of seven primer combinations with the presumed unrelated female 2 . Female 1 and female 2 differed at 20 marker loci of seven primer combinations. Since this is the first time an AFLP analysis was performed on $P . m$. bivittatus, it is not clear whether this level of polymorphism for AFLP markers is normal for this snake species or whether the adults kept at the zoo are inbred or related. Nevertheless, the young are genetically identical to their mother and do not show markers that suggest the involvement of a father. It therefore is highly unlikely that the eggs were fertilized through sperm storage.

\section{Discussion}

We present four lines of evidence that the Burmese python is capable of parthenogenetic reproduction: (i) offspring are genetically identical to their mother, (ii) all offspring are female, (iii) the mother has been raised in the absence of males, although we cannot completely exclude the possibility that she has been in contact with males during her first 2 years, and (iv) the percentage of 
Table 2 The number of marker differences between individuals listed for each of the eight primer combinations

\begin{tabular}{|c|c|c|c|c|c|c|}
\hline \multicolumn{2}{|c|}{ Primer combination } & \multirow{2}{*}{$\begin{array}{l}\text { Total no. } \\
\text { of markers }\end{array}$} & \multicolumn{4}{|c|}{ No. of markers only present in the first individual, no. of markers only present in the second individual } \\
\hline & & & Young vs mother & Mother vs female 1 & Mother vs female 2 & Female 1 vs female 2 \\
\hline \multirow[t]{4}{*}{ Pst-ACC with } & Taq-AA & 90 & 0,0 & 0,1 & 2,0 & 3,0 \\
\hline & Taq-AC & 99 & 0,0 & 2,6 & 3,6 & 4,3 \\
\hline & Taq-AG & 124 & 0,0 & 5,2 & $*$ & $*$ \\
\hline & Taq-AT & 101 & 0,0 & 6,1 & 3,5 & 3,0 \\
\hline \multirow[t]{5}{*}{ Pst-AGA with } & Taq-AA & 56 & 0,0 & 1,0 & 1,0 & 0,0 \\
\hline & Taq-AC & 81 & 0,0 & 0,1 & 0,4 & 0,3 \\
\hline & Taq-AG & 94 & 0,0 & 0,3 & 1,3 & 3,0 \\
\hline & Taq-AT & 47 & 0,0 & 1,0 & 2,0 & 1,0 \\
\hline & Total & 692 & 0,0 & 15,14 & $12^{*}, 19^{*}$ & $13^{*}, 7^{*}$ \\
\hline
\end{tabular}

A marker is scored as different if it is present in one and absent in the other of the pair. For each pairwise comparison, the number of variable markers scored as present is indicated for each individual. The asterisks indicate cases where primer combination Pst-ACC with Taq-AG did not amplify in female 2; total should therefore be approximately $1 / 7$ higher.

Table 3 Parental genotypes in combination with the expected offspring phenotypes, as they can be observed for the different modes of reproduction when a dominant marker as AFLP is used

\begin{tabular}{|c|c|c|c|c|}
\hline \multicolumn{2}{|c|}{ Parental genotype } & \multirow[b]{2}{*}{ Sex } & \multicolumn{2}{|c|}{ Offspring phenotypes } \\
\hline Potential father & Mother & & $\begin{array}{c}\text { Parthenogenesis; } \\
\text { homozygous offspring }\end{array}$ & $\begin{array}{c}\text { Parthenogenesis; } \\
\text { heterozygous offspring }\end{array}$ \\
\hline 11 & 11 & 1 & 1 & 1 \\
\hline 11 & 10 & 1 & 1 and $0^{*}$ & 1 \\
\hline 11 & 00 & $1^{*}$ & 0 & 0 \\
\hline 01 & 11 & 1 & 1 & 1 \\
\hline 01 & 01 & 1 and $0^{*}$ & 1 and $0^{*}$ & 1 \\
\hline 01 & 00 & $1^{*}$ and 0 & 0 & 0 \\
\hline 00 & 11 & 1 & 1 & 1 \\
\hline 00 & 01 & 1 and $0^{*}$ & 1 and $0^{*}$ & 1 \\
\hline 00 & 00 & 0 & 0 & 0 \\
\hline
\end{tabular}

1 means character present, 0 means character absent. Parthenogenesis produces either complete homozygous offspring or offspring in which the heterozygozity of the mother is retained (Suomalainen et al, 1987). *Mother and offspring phenotype combinations that were not found in this study.

eggs that develops into an embryo has remained constant over the past 5 years.

The distinction between sexual and parthenogenetic reproduction is based on the detection of forbidden genotypes (Table 3 ). The young show only maternal markers while there is a 29 markers difference between the mother and her half-sister (female 1). In addition, the probability that males are absent from a clutch of six produced by sexual reproduction is less than $1 / 2^{6} \approx 0.017$, assuming that the normal sex ratio is $1: 1$. An alternative mechanism that could explain the deviation of a 1:1 sex ratio is temperature-dependent sex determination, but this has never been reported for the Boidae. These observations suggest that this female python is parthenogenetic.

The robustness of our genetic approach depends upon the amount of genetic variation and the number of markers. We have scored almost 700 AFLP markers, but the low level of genetic variation between the presumed unrelated female 2 and the other two females suggests that the captive animals in Artis Zoo are inbred. Given this low level of genetic differentiation and the uncertainty about the first 2 years of the mother, we must evaluate the worst-case scenario that the mother has mated with a related male. In order to explain the identical fingerprints of mother and offspring in case of sexual reproduction, the fingerprint of the father must have had the following genetic properties: (i) the male did not have a marker present (11) that was absent in the mother, (ii) if the father had such a marker (10), he did not transmit it to any of the young, and (iii) at least one of the parents was homozygous present (11) for each of the 692 markers. Ideally, we would like to calculate the likelihood of the putative male genotype. This requires at least information on allele frequencies. Unfortunately, this information is not available. Instead, we argue that sexual reproduction is unlikely in the case of this python by considering two special male genotypes.

If the mother is entirely homozygous for all markers as a result of inbreeding and she has mated with her brother, fertilization of her eggs with retained sperm can result in an offspring that is genetically identical to her. In this case, the complete homozygosity and identity of both parents would explain the lack of segregation of heterozygous markers in the offspring. However, the genetic data we present exclude the possibility that both parents are inbred and homozygous. If they were raised from a fully inbred line, the mother would share at least 
one allele with her half-sister (female 1) at the PM-1 microsatellite locus, but they share none. Additionally, the mother is not expected to show any AFLP marker that is absent in her half sister; we found 15 markers in the mother that her half-sister lacks.

There are several mechanisms in parthenogenetic animals that maintain diploidy in the gametes despite meiosis (Suomalainen et al, 1987). Mechanisms that result in completely homozygous individuals are excluded as the mechanism of parthenogenesis in the Burmese python, because there is no segregation of sex chromosomes and AFLP makers in the offspring: all offspring are female (ZW) and have identical AFLP fingerprints. Three other mechanisms, viz., central fusion, premeiotic doubling, and fusion of the first polar nucleus with the nucleus of the secondary oocyte, are all expected to result in offspring that are genetically identical to the mother. Cytological studies should allow distinction between these three mechanisms.

The finding that the young are genetically identical to their mother differs from previous reports on sporadic parthenogenesis in other snake species (Dubach et al, 1997; Schuett et al, 1997). In those studies, the offspring showed fewer (minisatellite fingerprint) markers than their mothers. In addition, all offspring were male and no female offspring were present. The authors suggested that the cytological mechanism through which the male young become completely homozygous and, consequently, the markers are lost is terminal fusion. In this study, none of the maternal markers was lost. Assuming that the mother is not homozygous for all markers (see above), the meiotic mechanism that produces the diploid egg cell in the pythons is thus different from the one in the previous studies. Consequently, instead of being male, the young are expected to be of the female sex. Upon dissection of six embryos they all indeed contained ovaries.

In an ideal situation additional evidence for parthenogenesis would have been obtained from replicate experiments. The mode of reproduction should be studied for a large number of individuals raised under different conditions and crossing experiments should be done. Unfortunately, these kinds of experiments are practically impossible in this species because of the large size of the adult snakes (4-5 m long and $40 \mathrm{~kg}$ ), the long time to reach maturity (5 years), and the fact that it is difficult to get them to reproduce in captivity.

Facultative parthenogenesis in snakes was only recently described (Schuett et al, 1997). The number of species in which a genetical analysis has been performed to rule out sperm retention is still very small (see Introduction), but anecdotal accounts of reproduction after long time isolation are numerous. This suggests that the actual list of species capable of facultative parthenogenesis may be much longer. This suggestion is further supported by the fact that the cases in which parthenogenesis has been proven with molecular genetical techniques are from some quite different families. Reevaluating reports on long-term sperm retention in isolated females living in captivity have the highest chance to successfully reveal new cases of facultative parthenogenesis.

We have demonstrated that $P . m$. bivittatus is able to reproduce asexually in captivity. The mode of parthenogenesis in this species, as opposed to reported facultative parthenogenetic snake species, is particularly elegant since offspring are clones of their mother and no genetic variation is lost. However, this snake lives in a highly controlled environment with abundant food. The evolutionary significance of parthenogenetic reproduction in the Burmese python is unclear since we have no information on the occurrence of parthenogenetic reproduction in wild populations, where females have access to mates and environmental conditions are variable.

\section{Acknowledgements}

We thank the staff and keepers of the Artis Zoo, Amsterdam, for providing samples and information in fine cooperation; $S$ Menken for his comments on an earlier version of this manuscript; $\mathrm{P}$ Kuperus and other laboratory collaborators for their help and advise on the laboratory work; M Kik of the University of Utrecht for her help with the sex determination of the embryos; J Albright and E Burns for sending us their microsatellite primers. This work was funded by the Institute for Biodiversity and Ecosystem Dynamics, University of Amsterdam.

\section{References}

Birkhead TR, Møller AP (1993). Sexual selection and the temporal separation of reproductive events: sperm storage data from reptiles, birds and mammals. Biol J Linn Soc 50: 295-311.

Burns EL, Houlden BA (1999). Isolation and characterization of microsatellite markers in the broad-headed snake Hoplocephalus bungaroides. Mol Ecol 8: 520-521.

Cuellar O (1971). Reproduction and the mechanism of meiotic restitution in the pathenogenetic lizard Cnemidophorus uniparens. J Morphol 133: 139-165.

Darevsky IS, Kupriyanova LA, Uzzel T (1985). Parthenogenesis in reptiles. In: Gans C, Billett F (eds) Biology of the Reptilia, John Wiley and Sons: New York. Vol 15, pp 411-526.

Dubach J, Sajewicz A, Pawley R (1997). Parthenogenesis in the Arafuran Filesnake (Acrochordus arafurae). Herpetol Nat Hist 5: 11-18.

Fox H (1976). The urinogenital system of reptiles. In: Gans C, Parsons TS (eds) Biology of the Reptiles, Academic Press. London and New York. Vol 6, pp 1-157.

Giannasi N, Thorpe RS, Malhotra A (2001). The use of amplified fragment length polymorphism in determining species trees at fine taxonomic levels: analysis of a medically important snake, Trimeresurus albolabris. Mol Ecol 10: 419-426.

King RB, Milstead WB, Gibbs HL, Prosser MR, Burghardt GM, McCracken GF (2001). Application of microsatellite DNA markers to discriminate between maternal and genetic effects on scalation and behaviour in multiple-sired garter snake litters. Can J Zool 79: 121-128.

Lougheed SC, Gibbs HL, Prior KA, Weatherhead PJ (2000). A comparison of RAPD versus microsatellite DNA markers in population studies of the Massasauga Rattlesnake. J Hered 91: 458-463.

MacCulloch RD, Murphy RW, Kupriyanova LA, Darevsky IS (1997). The Caucasian rock lizard Lacerta rostombekovi: a monoclonal parthenogenetic vertebrate. Biochem Syst Ecol 25: 33-37.

Magnusson WE (1979). Production of an embryo by an Acrochordus javanicus isolated for years. Copeia 1979: 744-745.

McCracken GF, Burghardt GM, Houts SE (1999). Microsatellite markers and multiple paternity in the garter snake Thamnophis sirtalis. Mol Ecol 8: 1475-1479.

Mueller UG, Wolfenbarger L (1999). AFLP genotyping and fingerprinting. Trends Ecol Evol 14: 389-394. 
Prosser MR, Gibbs HL, Weatherhead PJ (1999). Microgeographic population structure in the northern water snake, Nerodia sipedon sipedon detected using microsatellite DNA loci. Mol Ecol 8: 329-333.

Quellar DC, Strassman JE, Hughes CR (1993). Microsatellites and kinship. Trends Ecol Evol 8: 285-288.

Scalka P, Vozenilek P (1986). Case of parthenogenesis in water snakes, Nerodia sipedon. Fauna Bohemiae 11: 81-82.

Schuett GW, Fernandez PJ, Gergits WF, Casna NJ, Chizar D, Smith HM et al (1997). Production of offspring in the absence of males: evidence for facultative parthenogenesis in bisexual snakes. Herpetol Nat Hist 5: 1-10.
Suomalainen E, Saura A, Lokki J (1987). Cytology and Evolution in Parthenogenesis. CRC Press: Boca Raton, FL.

Vos P, Hogers R, Bleeker M, Reijans M, Van de Lee T, Hornes M et al (1995). AFLP: a new technique for DNA fingerprinting. Nucleic Acids Res 23: 4407-4414.

Weeks AR, Marec F, Breeuwer JAJ (2001). A mite species that consists entirely of haploid females. Science 292: 2476-2482.

Weeks AR, Van Opijnen T, Breeuwer JAJ (2000). AFLP fingerprinting for assessing intraspecific variation and genome mapping in mites. Exp Appl Acarol 24: 775-793. 